\title{
METODOLOGIAS ATIVAS E DIALOGICIDADE NA DIFUSÃO DAS BASES DA EDUCAÇÃO PROFISSIONAL E TECNOLÓGICA
}

\author{
Átila Alixandre de Moraes ${ }^{1}$ \\ Odair Diemer ${ }^{2}$ \\ DOI: https://doi.org/10.36524/profept.v5i2.739
}

\section{RESUMO}

Ingressantes dos Institutos Federais e a comunidade em geral apresentam divergência de compreensão sobre o que seria a Educação Profissional e Tecnológica (EPT). Assim, a pesquisa teve como objetivo analisar se metodologias ativas e dialogicidade podem contribuir para a difusão das bases que norteiam a EPT no Brasil. Para a realização da pesquisa foi ofertado ao público em geral uma formação fundamentada em metodologias ativas e dialogicidade sobre as bases que norteiam a EPT, sendo aplicada no IFMS campus Coxim. Durante a formação os participantes registraram suas impressões e opiniões em um diário reflexivo e em anotações de relatos para análise de conteúdo temática. Em síntese, houve indicativos que a metodologia utilizada colaborou com o entendimento e difusão das bases da EPT.

Palavras-chave: Ensino Técnico, Formação Integral, Politecnia, Omnilateralidade.

\section{ACTIVE METHODOLOGIES AND DIALOGICITY IN THE DIFFUSION OF THE BASES OF PROFESSIONAL AND TECHNOLOGICAL EDUCATION}

\begin{abstract}
The new students of Federal Institutes and the community in general have a divergent understanding of what would be the Professional and Technological Education (EPT). Thus, the research aimed to analyze whether active methodologies and dialogicity can contribute to the diffusion of the bases that guide EPT in Brazil. In order to carry out the research, a training based on active methodologies and dialogicity on the bases that guide the EFA was offered to the general public, being applied at the IFMS campus Coxim. During the training, participants recorded their impressions and opinions in a reflective diary and in annotations of reports for thematic content analysis. In general, there were indications that the methodology used collaborated with the understanding and diffusion of the bases of EPT.
\end{abstract}

Keywords: Technical Education, Integral Training, Polytechnic, Omnilaterality.

\footnotetext{
${ }^{1}$ Secretaria de Estado de Educação de Mato Grosso do Sul (SED/MS). E-mail: atila.131976@sed.ms.gov.br

2 Instituto Federal de Mato Grosso do Sul (IFMS) - Campus Coxim. E-mail: odair.diemer@ifms.edu.br
} 


\section{INTRODUÇÃO}

A Educação Profissional e Tecnológica (EPT) no Brasil é marcada por momentos de conquistas e retrocessos. Na década de 1970, com a Lei de Diretrizes e Bases (LDB) 5.692/71 até a LDB de 1996, o ensino técnico esteve praticamente a serviço do mercado e distante de uma formação integral (OLIVEIRA, 2009). Em 1997, foi publicado o Decreto n. 2.208/1997 que previa a EPT de forma concomitante e subsequente, mantendo um caráter dual, sendo considerado como um grande retrocesso para a educação profissional (MORAES \& DIEMER, 2019).

No início dos anos 2000, o Brasil passa por uma guinada histórica nas eleições presidenciais, com a eleição do então candidato Lula, do Partido dos Trabalhadores que prometia uma educação diferente da ofertada historicamente no país. Logo após sua eleição, às discussões sobre os caminhos da EPT são debatidas intensamente (MENDES, 2011).

Em 2008, por meio da Lei 11.892, o Governo Federal institui e amplia a Rede Federal de Educação Profissional e Tecnológica, criando os Institutos Federais. A EPT, então, tem como um de seus objetivos a formação integral do indivíduo. Todavia, para a operacionalização deste ensino é preciso novas práticas pedagógicas com metodologias engajadas na formação integral (ARAÚJO \& FRIGOTTO, 2015).

Repensar as práticas de aprendizagem para atender as demandas da EPT requer uma “travessia" para uma formação integral, exigindo práticas pedagógicas que proporcionem a autonomia do sujeito (MOURA, LIMA SILVA \& FILHO, 2015). Uma possibilidade para essa superação perpassa por uma relação entre educador-educando pautada na prática da dialogicidade, uma vez que este é um elemento importante para emancipação e na construção dos saberes de forma ativa e crítica (SANTOS, 2014; FREIRE, 2019).

Metodologias ativas, de acordo com Berbel (2011), podem despertar no estudante a curiosidade, buscando na autonomia um aporte para mudanças necessárias no processo de ensino e aprendizagem. As práticas de aprendizagem ativas, por meio de diálogos, problematizações, podem levar os participantes do processo a busca de soluções e o entendimento daquilo que os cerca, pois estarão sendo ativos no seu próprio processo de formação (MITRE et al., 2008). A transmissão do conhecimento em sala de aula ou em 
qualquer ambiente de ensino formal ou não-formal, não proporcionam uma aprendizagem pautada numa relação horizontal entre os atores do processo e, as metodologias ativas surgem para tornar o educando, agente ativo da construção do seu conhecimento (ANDRADE \& FERRETE, 2019).

Entende-se que é necessário levar para a sociedade o conhecimento sobre as bases conceituais da EPT, pois há fortes indícios que parte da sociedade, até mesmo ingressantes dos Institutos Federais desconhecem as premissas da EPT (SOUZA \& RODRIGUES, 2017). Nesse contexto, Costa e Filho (2018) salientam que a educação profissional a partir de 2004 avançou, porém o desconhecimento da EPT nas formações docentes é uma grande falha e, em partes, contribuem para a manutenção da incompreensão acerca da EPT. Deste modo, a presente pesquisa teve como objetivo analisar se metodologias ativas e dialogicidade podem contribuir para o entendimento e difusão das bases conceituais que norteiam a EPT no Brasil

\section{PERCURSO METODOLÓGICO}

O projeto foi iniciado com uma revisão bibliográfica sobre a concepção de ensino médio integrado, educação profissional e tecnológica, metodologias ativas e dialogicidade. Para tanto, foram acessados os sites "Periódicos Capes" e "Google Acadêmico" e como termos de pesquisa: Institutos Federais, Ensino Médio Técnico Integrado, Educação Profissional e Tecnológica, metodologias ativas (Rotação de estações de aprendizagem e World Café) e dialogicidade. O material bibliográfico pesquisado serviu como base para elaboração da formação.

Para a realização da pesquisa foi ofertado ao público em geral uma formação fundamentada em metodologias ativas e dialogicidade sobre as bases que norteiam a EPT no Brasil, sendo a formação aplicada no Instituto Federal de Mato Grosso do Sul (IFMS) campus Coxim, nos dias 28 e 29 de novembro de 2019, no período noturno das $18 \mathrm{~h} 45 \mathrm{~min}$ às $22 \mathrm{~h} 45 \mathrm{~min}$, totalizando uma carga horária de oito horas. O projeto de pesquisa foi submetido ao Comitê de Ética (CEP) por meio da Plataforma Brasil e aprovado com o CAEE 20544719.0.0000.0021.

O período de inscrições foi entre os dias 18 e 27 de novembro de 2019. A divulgação aconteceu por meio de chamadas in loco nas instituições de ensino superior do município e por mídias sociais, sendo disponibilizadas 20 (vinte) vagas, tendo como público-alvo discentes e 
docentes do campus e de outras instituições interessados no tema e às inscrições foram efetivadas por meio do Google Formulários.

A formação foi organizada em três momentos, de acordo com Vieira e Volquind (2002): 1) Contextualização, 2) Planificação e 3) Reflexão. A contextualização foi a discussão da temática por meio do diálogo entre educador-educando. Na planificação, os envolvidos mensuram o problema, investigam por meio, do diálogo, de técnicas e métodos definidos pelo professor, que torna-se mediador. Por último a reflexão, quando a sistematização do conhecimento é elencada, por meio de produções dos estudantes.

As técnicas para os três momentos foram baseadas em metodologias ativas, como "Rotação por Estações" (VALENTE, 2014; STEINERT \& HARDOIM, 2017; PEREIRA \& SILVA, 2018) e "World Café" (TEZA et al., 2013; MACHADO \& PASSOS, 2018) sempre circundadas por práticas dialógicas. Ressalta-se que as técnicas e metodologias utilizadas para cada momento são fomentadas a partir de métodos que proporcionaram aos participantes, interação, aprendizagem entre os pares, integração, protagonismo e autonomia na construção do conhecimento e a indissociabilidade entre teoria e prática.

Durante a formação os participantes registraram suas impressões e opiniões em um diário reflexivo e em anotações de relatos na dinâmica "Word Café" que foram utilizados para análises da efetividade da formação e também sobre a importância dos temas debatidos. Para tanto, o diário e os relatos foram avaliados por meio da análise de conteúdo temática conforme Bardin (2016).

\section{RESULTADOS E DISCUSSÃO}

No ato da inscrição, os participantes informaram algumas situações, respondendo questionamentos objetivos, tais como: formação acadêmica, instituição de ensino que pertence e se já tinham estudado ou conheciam as Bases da Educação Profissional e Tecnológica no Brasil. O objetivo, além de controlar o quantitativo de inscritos, conhecer o público participante e coletar informações pertinentes para o desenvolvimento da formação.

Quanto à formação acadêmica, a maioria dos inscritos foi constituída por estudantes com Ensino superior incompleto, ou seja, que estavam cursando alguma graduação, que correspondeu a um total de 48,1\%, seguida por Ensino superior completo e Pós-graduação Lato 
Sensu com 18,5\% cada, Pós-graduação Stricto Sensu Mestrado com 7,4\% e Ensino médio incompleto com $3,7 \%$ dos inscritos.

Praticamente a metade dos inscritos foi de estudantes de graduação, evidenciando que a maior parte dos cursos superiores especialmente os de licenciatura não discutem a EPT em seus currículos, exceção que deve ser mencionada é o curso de licenciatura em química do IFMS campus Coxim. Tal evidência, também foi observado por Carvalho \& Souza (2014) ao relatarem ausência de unidades curriculares específicas sobre a educação profissional no currículo de muitos cursos de Pedagogia e Faculdades de Educação.

O público participante foi majoritariamente externo ao IFMS, apenas 14,8\% possuíam vínculo com o IFMS. Portanto, do total de inscritos 85,2\% foram de pessoas externas ao IFMS, sendo $63 \%$ de Universidades, consequentemente estudantes de cursos de graduação do Município de Coxim e 22,2\% de professores da Rede Estadual de Ensino. O município de Coxim possui várias instituições de ensino superior, públicas e privadas, que ofertam na sua maioria cursos de Licenciatura. Durante a divulgação do curso, estudantes dos cursos integrados do IFMS e de escolas da Rede Pública de Coxim foram convidados a participar, porém a participação concentrou-se na sua maioria em acadêmicos de outras instituições.

No ato da inscrição também foi questionado duas situações sobre a EPT no Brasil. A primeira: "Você conhece ou já estudou as Bases conceituais da Educação Profissional e Tecnológica do Brasil?’”. A intenção foi de coletar dados iniciais sobre o conhecimento dos participantes sobre a EPT. O questionamento foi objetivo, com três alternativas: sim, não e parcialmente, $51,9 \%$ responderam que não conheciam, $37 \%$ que conheciam parcialmente e $11,1 \%$ que conheciam.

A segunda: “O que você entende por Educação Profissional e Tecnológica?”. Para análise dos questionamentos, foi elaborado duas categorias: os que demonstraram algum domínio e os que não apresentaram domínio. Alguns cursistas elencaram total desconhecimento sobre o assunto e até mesmo uma confusão com a etimologia da palavra "Tecnológica", como o cursista $\mathrm{C} 1$ que respondeu "Um avanço na educação através da tecnologia". Todavia, o cursista $\mathrm{C} 2$ "É uma modalidade educacional caracterizada pela oferta de cursos técnicos e tecnólogos, a fim de formar pessoas omnilateralmente como cidadãos e profissionais para atuar no mercado de trabalho". Provavelmente esta resposta pode ter sido feita por alguém do IFMS, já que houve a participação de servidores do Campus e estudantes egressos dos cursos técnicos. 
Diante do exposto, fica demonstrado que mesmo o público sendo formado na sua maior parte por estudantes de cursos de licenciatura, há um certo desconhecimento sobre a EPT, desse modo, evidenciando uma lacuna na formação desses profissionais. De acordo Urbanetz (2012) apesar da ascensão e avanço da formação profissional e tecnológica no Brasil, esta, ainda, continua sendo uma ilustre desconhecida nas discussões sobre formação de professores. Para Souza \& Rodrigues (2017), mesmo com as políticas públicas para a formação profissional, além do desconhecimento sobre a EPT na formação, as especificidades desta modalidade de ensino impõem uma base pedagógica para orientar as práticas e, desse modo, trazendo uma característica que necessita de uma discussão aprofundada.

Na coleta de dados também foi questionado: Quais eram as expectativas com a formação que seria ofertado? Resposta do cursista C3: "Compreender a finalidade do EPT para agregar conhecimentos para a docência". Resposta do Cursista C4: "São grandes, principalmente porque vai ser uma via de mão dupla, tanto para ampliar o conhecimento, no sentido de oferecer uma aprendizagem mais significativa aos estudantes. E também para o meu crescimento pessoal e profissional”. Muitos relataram que esperavam conhecer a EPT e às práticas educativas que à permeiam. Assim, para o desenvolvimento da formação essas ponderações foram importantes.

Em ambos os encontros os participantes, além das discussões pertinentes, redigiam por meio de um diário suas impressões sobre o encontro e as técnicas utilizadas como facilitadora da discussão. No diário reflexivo do primeiro encontro, as ponderações foram enquadradas em duas categorias: ampliação de conhecimento sobre a EPT (tanto por citação direta ou por discorrer sobre algum conceito que se referia a EPT) e como as práticas educativas utilizadas contribuíram com o encontro.

\section{Categoria: Ampliação do conhecimento sobre a EPT}

No primeiro encontro 13 (treze) inscritos compareceram para a oficina, destes 07 (sete) mencionaram considerações sobre a ampliação de conhecimento sobre a EPT e 06 (seis) relataram a importância das metodologias utilizadas. Percebe-se, pelas anotações dos cursistas, que o termo "ampliação do conhecimento" foi utilizado em parte das produções: Reflexão cursista C1: "Os temas abordados durante a oficina pedagógica foi de grande valia para ampliar o conhecimento quanto docente sobre a educação profissional e tecnológica no Brasil. [...]”. 
Reflexão Cursista C2: “Cheguei para a oficina tendo em mente uma vaga noção do que era a educação profissional tecnológica. Ao longo da oficina fui adquirindo junto aos participantes o que seria o tema central da oficina".

Reflexão Cursista C3: "O encontro de hoje revelou-se muito proveitoso, pois serviu para ratificar alguns conhecimentos que já havia adquirido sobre as bases da EPT em leituras realizadas por conta própria. Ter, porém, a oportunidade de discutir com outros docentes e compartilhar pontos de vistas sobre a formação integral em contraponto com a tradicional foi de grande valia para minha formação"[...] Com o resultado das discussões travadas hoje, ficou claro o papel transformador da EPT, na medida em que forma cidadãos mais críticos, autônomos e melhor preparados para atuação em sociedade".

Reflexão Cursista C4: “A educação profissional e tecnológica visa formar o indivíduo na sua integralidade. Diante dessa proposta, a formação parte de um conjunto de ações que implicam em mudanças inovadoras e dinâmicas onde o cidadão possa ser protagonista dessas ações".

Sendo assim, há indícios que os cursistas apresentaram em suas anotações a ampliação do saber em relação ao assunto principal do encontro, apresentando desde ponderações diretas do que contribuiu para o seu conhecimento e alguns utilizando conceitos que permeiam a EPT. Corroborando com Soares (2005) ao afirmar que a partir de informações analisadas em diários reflexivos os estudantes conseguiram refletir sobre sua aprendizagem, se posicionando em relação a aspectos que julgavam mais importantes.

\section{Categoria: como as práticas educativas utilizadas contribuíram com o encontro.}

Sobre os que mencionaram sobre as metodologias utilizadas no primeiro encontro: Reflexão Cursista C1: "As dinâmicas usadas contribuíram ainda mais para ampliar meus conhecimentos uma vez que discutimos entre grupos ideias e opiniões diferentes para construção eficaz das temáticas abordadas".

Reflexão Cursista C2: "As dinâmicas usadas, contribuiu e me ajudou muito a entender melhor os conceitos apresentados como diálogo e trocas de ideias, para a formação de um novo conhecimento". 
Reflexão Cursista C3: “A metodologia utilizada para conduzir a oficina (rotação por estações), permitiu que os conhecimentos fossem construídos de maneira mais significativa, na medida em que todo o processo se deu por meio de um alto nível de interação entre os cursistas".

Reflexão Cursista C4: “A dinâmica utilizada entre nós foi de grande conhecimentos pois nos colocou para transmitir o conhecimento e não ficou somente sentado ouvindo através da metodologia conseguimos pensar e transmitir. Saio com um conhecimento muito maior.

Reflexão Cursista C5: “Ao longo da oficina, fui adquirindo junto aos participantes o que seria o conceito tema da oficina. Ao final, pude perceber que a metodologia, meu conhecimento foi sendo construído e não imposto e acredito que isso é uma das finalidades desse tipo de ensino".

Portanto, há indicativos por meio da análise, que a metodologia e as dinâmicas proporcionaram uma reflexão dos participantes sobre o assunto abordado e como este foi trabalhado. As formações curtas são oportunidades de vivenciar situações concretas, quebrando a aprendizagem focada apenas na cognição, no qual o participante conhece, pensa, age e, assim, todos se apropriam, constroem e produzem, buscando a superação da dicotomia teoria e prática (PAVIANI \& FONTANA, 2009).

O segundo encontro que ocorreu no dia 29 de novembro de 2019, o tema central foi: "o mundo do trabalho e a educação profissional”, os participantes foram conduzidos a refletirem, por meio de dialogicidade e métodos ativos de aprendizagem, sobre como o ensino integrado e as metodologias ativas poderiam contribuir para a formação na EPT e para o mundo do trabalho. A técnica utilizada foi uma conversação estruturada com aprendizagem por pares, distribuídas por duas mesas e com um relator fixo das discussões. A cada rodada, o relator permanecia anotando as considerações gerais do grupo sobre os questionamentos. Para preservar a identidade dos participantes, os relatos foram identificados por Relatos I e II. O questionamento I: "Como o ensino integrado pode contribuir para o mundo do trabalho?"

Relato I sobre o primeiro questionamento: “O aluno deve ser incentivado para aprender de forma autônoma e participativa, a partir de situações reais". Situações problemas que envolva os estudantes a partir de novos desafios. Projetos como forma de adquirir conhecimento com o conceito de aprender a fazer. 
Relato II sobre o primeiro questionamento: “[...] os conhecimentos adquiridos nessa forma de ensino, pode contribuir na melhora do ambiente de trabalho da região". Percebe-se que a partir das leituras e discussões sobre a temática do encontro, parte dos participantes mensuraram o ensino integrado com a indissociabilidade entre teoria e prática como uma contribuição importante para o ensino integrado.

O segundo questionamento da dinâmica consistia em os participantes, após a leitura e discussão do texto de apoio deveriam refletir sobre o seguinte questionamento: Como as metodologias ativas podem contribuir para o ensino técnico?

Relato I sobre o questionamento II: "pode contribuir com a autonomia do estudante e com a construção do conhecimento colaborativo".

Relato II sobre o questionamento II: "Promover a integração de todos espaços e tempo, gerando profissionais que pensem de formas variadas para resolver um problema".

As metodologias ativas, de acordo com Berbel (2011), além de sua praticidade para lidar com os mais variados assuntos, contribuem significativamente com a promoção da autonomia dos estudantes, uma vez que são levados a vivenciarem, refletirem e posicionarem perante aos assuntos abordados ou a problemas apresentados. Sendo assim, há indícios por meio dos relatos da discussão que os participantes conseguiram vivenciar e compreender como os métodos ativos podem contribuir para o ensino integrado.

Para finalizar a formação, os participantes refletiram sobre o encontro e sobre o curso de modo geral, sendo que seus relatos foram categorizados em duas situações: ensino integrado e como as metodologias ativas podem contribuir para a formação integral.

\section{Categoria: ensino integrado}

Dos dez participantes do segundo encontro, sete apresentaram nos seus relatos como o ensino integrado, uma das premissas da EPT, podem contribuir para o mundo do trabalho e três apresentaram considerações sobre as metodologias utilizadas e como essas podem auxiliar na formação integral.

Reflexão Cursista C1: "O ensino integrado contribui muito para o mundo do trabalho porque formam cidadãos críticos, participativos, autônomos preparando intelectualmente para os novos desafios profissionais. 
Reflexão Cursista C2: “O ensino integrado está para qualificar as pessoas tanto no social, econômico e para sua formação acadêmica capaz de dialogar e criticar e sugerir soluções.

Reflexão Cursista C3: "O ensino integrado pode contribuir de forma ampla porque visa formar os indivíduos na sua totalidade".

Considerando as informações coletadas, percebe-se que a metodologia do segundo encontro conseguiu demonstrar como o ensino integrado pode contribuir para a formação e o mundo do trabalho. De acordo com Oliveira (2009), o ensino integrado, tem como desafio não apenas formar para o mercado do trabalho, mas também proporcionar aos jovens e a sociedade no geral, cidadãos capazes de serem criativos, críticos e autônomos.

\section{Categoria: como as metodologias ativas podem contribuir para a formação} integral.

Sobre a categoria II, na qual os participantes elencaram pontos importantes das metodologias ativas para o ensino integrado, as percepções dos cursistas foram:

Reflexão Cursista C1: "Neste encontro de hoje percebeu-se que o ensino integrado as metodologias ativas, apontam para a construção de um conhecimento autônomo, mas vinculado com a realidade. Um dos pilares para a construção do conhecimento a partir de metodologias ativas encontra-se na interação".

Reflexão Cursista C2: “As metodologias apresentadas nesse curso, passou uma ideia de que as práticas podem ser diferenciadas e provocativas, trazendo assim uma formação na integralidade e plenitude para o conhecimento.

As considerações apresentadas pelos participantes no segundo encontro corroboram com Araújo e Frigotto (2015), que qualquer meio, independente de questões ideológicas e aplicabilidade podem contribuir para uma formação integral na EPT. As metodologias ativas surgem como meios para contrapor o ensino tradicional, pautado na memorização e centralidade no professor, colaborando para uma participação ativa de todos (FINI, 2018).

Considerando os resultados positivos da pesquisa, espera-se que este trabalho inspire e sirva de modelo para ser utilizado e aplicado em outras instituições que compõem a Rede Federal de Educação Profissional e Tecnológica, pois contribui para a difusão da EPT com 
práticas educativas que visam promover uma formação integral, pautada na autonomia e protagonismo dos estudantes.

\section{CONSIDERAÇÕES FINAIS}

As concepções da Educação Profissional e Tecnológica praticada nos Institutos Federais ainda é uma desconhecida para parte da comunidade acadêmica, estudantes de licenciatura e sociedade no geral, mesmo com o substancial aumento de programas de Pós-Graduação e trabalhos científicos acerca do assunto.

Este trabalho apresentou, por meio dos dados levantados, que a EPT praticada a partir do Decreto n ${ }^{\circ} 5.154$ de 2004 juntamente com a Lei 11.892 de 2008 que instituiu a Rede Federal de Educação Profissional e Tecnológica necessita ser mais difundida junto à sociedade, em especial, nos cursos de licenciatura das Instituições de Ensino superior.

As práticas dialógicas e as metodologias ativas foram importantes para a construção do conhecimento ao longo do desenvolvimento da formação. Assim, houve indicativos que a formação aplicada colaborou no entendimento das premissas da educação profissional e tecnológica e as práticas educativas usadas corroboraram com uma maior interação, integração e diálogo entre os participantes.

\section{REFERÊNCIAS}

ANDRADE, L; G; S; B; FERRETE, R; B. Metodologias Ativas e a Educação Profissional e Tecnológica: invertendo a sala de aula em vista de uma aprendizagem significativa. Educação Profissional e Tecnológica em Revista, v. 3, n 2, p. 86 - 98, 2019.

ARAUJO, R.; M.; L.; FRIGOTTO, G. Práticas pedagógicas e ensino integrado. Revista Educação em Questão, v. 52, n. 38, p. 61-80, 2015.

BARDIN, L.. Análise de conteúdo. São Paulo: Edições 70, 2016.

BERBEL, N.. As metodologias ativas e a promoção da autonomia de 53 estudantes. Semina: Ciências Sociais e Humanas, v. 32, n. 1, p. 25-40, 2011.

CARVALHO, O. F. \& SOUZA, F. H. M.. Formação do docente da educação profissional e tecnológica no Brasil: Um diálogo com as faculdades de educação e o curso de pedagogia. Educação \& Sociedade, v. 35, nº 128, p. 629-996, 2014.

COSTA, M. A; FILHO, A. M. Políticas de formação para professores para a Educação Profissional: cem anos de lutas. Ensino Em Revista Uberlândia, MG v.25 n. Especial p. 11131136, 2018. 
FINI, M. Metodologias inovadoras de aprendizagem e suas relações com o mundo do trabalho: desafios para a transformação de uma cultura. Administração: ensino e pesquisa, v. 19, p. 176-183, 2018.

FREIRE, P.. Pedagogia do Oprimido. 67ª ed. Rio de Janeiro/São Paulo: Paz e Terra, 2019.

MACHADO, M. P. M.; PASSOS, M. F. D. O uso do world café como método de pesquisa junto às equipes de saúde. Revista Brasileira em Promoção da Saúde. v. 31, p. 1-10, 2018.

MENDES, A. C.. Reforma da Educação Profissional e as formulações e ações para as escolas criadas com o projeto de expansão da Rede Federal. Conexão Ciência. e Tecnologia, v. 5, n. 2, p. 24-31, 2011.

MITRE, S. M.; BATISTA, R. S.; MENDONÇA. J. M. J.; PINTO, N. M. M.; MEIRELLES. C. A. B.; PORTO, C. P.; MOREIRA, T.; HOFFMANNET, L. M. A.. Metodologias ativas de ensino-aprendizagem na formação profissional em saúde: debates atuais. Ciência \& Saúde Coletiva, v. 13, p. 2133-2144, 2008.

MOURA, D. H; LIMA FILHO, D. L.; SILVA, M. R. Politecnia e formação integrada: confrontos conceituais, projetos políticos e contradições históricas da educação brasileira. Revista Brasileira de Educação, v. 20, n. 63, p. 1057-1080, 2015.

MORAES, Á. A.; DIEMER, O. Bases Históricas da criação dos cursos técnicos integrado ao ensino médio no Brasil. História da Ciência e do Ensino - Construindo Interfaces. v. 20, p. 238-247, 2019.

OLIVEIRA, R. Possibilidades do Ensino Médio Integrado diante do financiamento público da educação. Educação e Pesquisa, p. 51-66, 2009.

PAVIANI, N. M. S.; FONTANA, N. M. Oficinas pedagógicas: relato de uma experiência. Conjectura, v. 14, n. 2, 2009.

PEREIRA, Z. T. G.; SILVA, D. Q. Metodologia Ativa: Sala de Aula Invertida e suas Práticas na Educação Básica. REICE. Revista Iberoamericana sobre Calidad, Eficacia y Cambio en Educación, n. 16, p. 63-78, 2018.

SANTOS, M. J. A dialogicidade no pensamento de Paulo Freire e de Hans Georg Gadamer e implicações na cultura escolar brasileira. Cadernos do PET Filosofia, v. 5, n.10, p. 1-11, 2014.

SOARES, M. F. Diários Escolares Reflexivos como Narrativas de Experiência de Aprendizagem. Contexturas: Ensino Crítico de Língua Inglesa. São Paulo, n 8, p.79-90, 2005.

SOUZA, F. C. S.; RODRIGUES, I. S.. Formação de professores para Educação Profissional no Brasil: Percurso Histórico e desafios contemporâneos. Revista HISTEDBR On-line, v. 17, n.2, p.621-638, 2017. 
STEINERT, M. É. P.; HARDOIM, E. L. Leigos ou excluídos? A criação de um aplicativo educacional e seu uso via ensino híbrido em uma escola pública. Revista SUSTINERE, Rio de Janeiro, v. 5, n. 1, p. 90-113, 2017.

TEZA, P.; MIGUEZ, V. B.; FERNANDES, R. F.; SOUZA, J. A.; DANDOLINI, G. A.; ABREU, A. F. Geração de ideias: aplicação da técnica world café. International Journal Knowledge Engineering and Management, v. 3, n. 3, p. 1-14, 2013.

URBANETZ, S. T. Uma ilustre desconhecida: a formação docente para a educação profissional. Revista Diálogo Educacional, v. 12, n. 37, p. 863-883, 2012.

VALENTE, J. A. Blended learning e as mudanças no ensino superior: a proposta da sala de aula invertida. Educar em Revista, Curitiba, Brasil, Edição Especial, p. 79-97, 2014.

VIEIRA, E.; VOLQUIND, L. Oficinas de ensino: O quê? Por quê? Como? 4. ed. Porto Alegre: Edipucrs, 2002. 